\title{
Comparative Study of Phases Forming in Niobium-Antimony Oxides System upon High Temperature Treatment and High-Energy Ball Milling
}

\author{
P. Dulian ${ }^{a, *}$, M. Piz $^{b}$, E. FilipeK ${ }^{b}$ And K. WieczoreK-Ciurowa ${ }^{a}$ \\ ${ }^{a}$ Cracow University of Technology, Faculty of Chemical Engineering and Technology, \\ Warszawska 24, 31-155 Kraków, Poland \\ ${ }^{b}$ West Pomeranian University of Technology Szczecin, Faculty of Technology and Chemical Engineering, \\ al. Piastów 42, 71-065 Szczecin, Poland
}

\begin{abstract}
The compound $\mathrm{SbNbO}_{4}$ that is formed in a ternary system of $\mathrm{Nb}-\mathrm{Sb}-\mathrm{O}$ has been obtained for the first time by high-energy ball milling of the equimolar mixture of oxides $\mathrm{Sb}_{2} \mathrm{O}_{3} / \mathrm{Nb}_{2} \mathrm{O}_{5}$ in argon atmosphere. This compound was characterised by X-ray diffraction, differential thermal analysis- thermal gravimetry, infrared, and scanning electron microscopy methods and its properties were compared with those of $\mathrm{SbNbO}_{4}$ also obtained as a result of high-temperature reaction between the same oxides and also in argon atmosphere. As shown by differential thermal analysis results, irrespective of the method of synthesis, $\mathrm{SbNbO}_{4}$ is stable in argon atmosphere up to $\approx 1125^{\circ} \mathrm{C}$ and in air up to $\approx 800^{\circ} \mathrm{C}$. The compound can be applied as a photocatalyst in the reaction of producing hydrogen from water.
\end{abstract}

DOI: $10.12693 /$ APhysPolA.126.938

PACS: 81.05.-t

\section{Introduction}

As follows from the information on the binary systems of niobium and antimony oxides, describable by the formula $\mathrm{Nb}-\mathrm{Sb}-\mathrm{O}$, there are no phases formed in this system in which both antimony and niobium would be at the highest oxidation state, +5 . The formation of the compounds $\mathrm{SbNbO}_{4}, \mathrm{Sb}_{3} \mathrm{Nb}_{3} \mathrm{O}_{13}$ and $\mathrm{Sb}_{0.67} \mathrm{Nb}_{2} \mathrm{O}_{6}$, in which antimony and/or niobium are at lower oxidation states has been reported and the formation of a solid solution $\mathrm{SbNbO}_{4}$ described by the formula $\mathrm{SbSb}_{x} \mathrm{Nb}_{1-x} \mathrm{O}_{4}$, where $0.0<x<1.0$ has been signalled [1-13]. With regard to its application potential, the most attention has been paid to $\mathrm{SbNbO}_{4}$ in which antimony is at +3 and niobium at +5 oxidation state. This compound was for the first time obtained in the 1960s by Roth and Waring [2] as a result of heating of oxides $\mathrm{Sb}_{2} \mathrm{O}_{3}$ and $\mathrm{Nb}_{2} \mathrm{O}_{5}$ mixture sealed in platinum ampoules, at temperatures from the range $995-1103{ }^{\circ} \mathrm{C}$ for many hours. According to the authors of [9] this compound can be obtained also by the solid state reaction when a mixture $\mathrm{Sb}_{2} \mathrm{O}_{3} / \mathrm{Nb}_{2} \mathrm{O}_{5}$ is heated in argon atmosphere at $900{ }^{\circ} \mathrm{C}$ for $2 \mathrm{~h}$. Single crystals of this compound have been also obtained by the hydrothermal method at temperatures from the range $400-450{ }^{\circ} \mathrm{C}$ under a pressure from the range 650 $670 \mathrm{~atm}[3-7]$. The structure of the compound $\mathrm{SbNbO}_{4}$ has been determined [6-9] and its physicochemical properties (including electric, magnetic, optical and photocatalytic ones) have been established [4-6, 9]. According to the updated results [9] it crystallises in the orthorhombic

\footnotetext{
${ }^{*}$ corresponding author; e-mail: piotrdulian@indy.chemia.pk.edu.pl
}

system $(a=5.568 \AA, b=11.811 \AA, c=4.938 \AA)$ and has a lamellar structure. $\mathrm{Nb}$ ions are octahedrally coordinated with the oxygen atoms to build $\mathrm{NbO}_{6}$ octahedra. They are connected by sharing four corners, and $\mathrm{Sb}^{3+}$ ions are located in between these octahedral layers. The $\mathrm{Sb}^{3+}$ ions are surrounded by six oxygen atoms, forming strongly distorted $\mathrm{SbO}_{6}$ [9]. It is known that $\mathrm{SbNbO}_{4}$ is a ferroelectric in the temperature range from $\approx 400$ to $\approx 600{ }^{\circ} \mathrm{C}[5]$ and that it shows photocatalytic activities for $\mathrm{H}_{2}$ evolution from water splitting [9]. For this reason it has been a subject of great interest.

Taking into regard the current state of knowledge on the properties of $\mathrm{SbNbO}_{4}$, and in particular its possible use a ferroelectric photocatalyst [9], the main aim of our study was to establish if this compound can be obtained by any other method than the hitherto used high-energy ball milling. As follows from the review on mechanochemistry [14] the methods based on this principle not only satisfy the criteria of green chemistry but they also permit a fast and easy synthesis of different composites, including those of micro- and nanomaterials of desired electric, magnetic and catalytic properties $[15,16]$.

This study was also undertaken to compare the fundamental physicochemical properties of $\mathrm{SbNbO}_{4}$ obtained from the equimolar mixture of $\alpha, \beta-\mathrm{Sb}_{2} \mathrm{O}_{3} / \mathrm{T}$ $\mathrm{Nb}_{2} \mathrm{O}_{5}$ by the mechanochemical method and by the hightemperature solid state reaction.

\section{Experimental}

\subsection{Materials synthesis, equipment and procedures}

The polycrystalline samples of $\mathrm{SbNbO}_{4}$ were prepared by using two different methods, namely: 
1. Mechanochemical synthesis (MChS) using laboratory planetary ball mill Pulverisette-6 (Fritsch $\mathrm{GmbH}$, Germany) with vessel and balls of zirconia, $\mathrm{rpm}=500, \mathrm{BPR}=1: 20$, time $=5 \mathrm{~h}$ and under argon atmosphere.

2. High-temperature synthesis (HTS) in a horizontal tube furnace (CTF 12/65/550, Carbolite, UK) in the atmosphere of deoxidised argon $(99.996 \%)$ flowing at the rate $5 \mathrm{dm}^{3} / \mathrm{h}$.

For the mechanochemical synthesis appropriate amounts of $\mathrm{T}_{-} \mathrm{Nb}_{2} \mathrm{O}_{5}$ and $\mathrm{Sb}_{2} \mathrm{O}_{3}$ (both of $99.99 \%$ purity, Aldrich, USA) were mixed in a stoichiometric molar ratio to $\mathrm{SbNbO}_{4}$ and then milled at the time of 1.5, 3.0, and $5.0 \mathrm{~h}$.

For the high-temperature synthesis the same reagents were mixed and pressed into pellet discs with $10 \mathrm{~mm}$ in diameter. These discs were heated in the atmosphere of argon at 600, 650, 700 in 24 h stages respectively. Both methods are described, inter alia, in the works [15-18].

\subsection{Characterization of as-synthesized materials}

The as-synthesized materials were analysed via a powder X-ray diffraction with a $\mathrm{Cu} K_{\alpha}$ source on an X'Pert and Empyrean Philips instrument, for $2 \theta=10^{\circ}-45^{\circ}$ with a step size of $0.02^{\circ}$. The identification of the material was made according to a JCPDS Table: 30-873, 5-534, 11-689, 86-2243.

The microstructure and morphology of the obtained polycrystals were examined with the use of an electron scanning microscope - SEM (JSM-6100, JEOL, Japan).

IR spectroscopy analysis was made by the use of Spectrometer (Specord M80, Carl Zeiss) (tablets with $\mathrm{KBr}$ in molar ratio 1:300).

The obtained samples were also subjected to examination by the differential thermal analysis-thermal gravimetric (DTA-TG) method with the use of a SDT 2960 apparatus, made by the TA Instruments Company. The measurements were taken in argon atmosphere, within the temperature range $20-1300^{\circ} \mathrm{C}$, at the heating rate of $10 \mathrm{deg} / \mathrm{min}$. The tests were conducted in corundum crucibles. The mass of the samples was $\approx 20 \mathrm{mg}$.

\section{Results and discussion}

As follows from analysis of phase composition (XRD) of the samples obtained after subsequent stages of mechanochemical synthesis from the equimolar mixture of oxides $\alpha, \beta-\mathrm{Sb}_{2} \mathrm{O}_{3} / \mathrm{T}-\mathrm{Nb}_{2} \mathrm{O}_{5}$ in argon (the commercial $\mathrm{Sb}_{2} \mathrm{O}_{3}$ is a mixture of two polymorphic varieties $\alpha$ and $\beta$ ), the monophase product containing only $\mathrm{SbNbO}_{4}$ was obtained after $5 \mathrm{~h}$ of high-energy ball milling. A comparison of the fragments of diffractograms obtained for the samples synthesised (Fig. 1), significant amount of $\mathrm{SbNbO}_{4}$ is formed in the reaction mixture already after $1.5 \mathrm{~h}$ of milling.

It has been also established that as a result hightemperature heating of the same mixture of the oxides

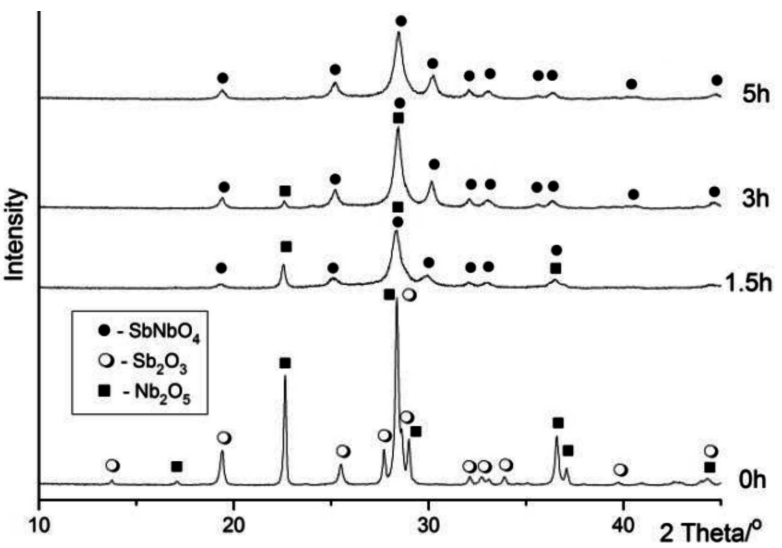

Fig. 1. Fragments of XRD diffractograms of the equimolar initial mixture of $\mathrm{Sb}_{2} \mathrm{O}_{3} / \mathrm{Nb}_{2} \mathrm{O}_{5}$ and the mixture after high-energy ball milling for $1.5,3.0$, and $5 \mathrm{~h}$.

in a tube furnace under flowing argon, the pure compound $\mathrm{SbNbO}_{4}$ is obtained after three $24 \mathrm{~h}$ stages of the reactants heating at 600,650 , and $700^{\circ} \mathrm{C}$. A fragment of XRD diffractogram of the equimolar mixture of $\mathrm{Sb}_{2} \mathrm{O}_{3} / \mathrm{Nb}_{2} \mathrm{O}_{5}$ and the product obtained after its heating at $700{ }^{\circ} \mathrm{C}(24 \mathrm{~h})$ is shown in Fig. 2.

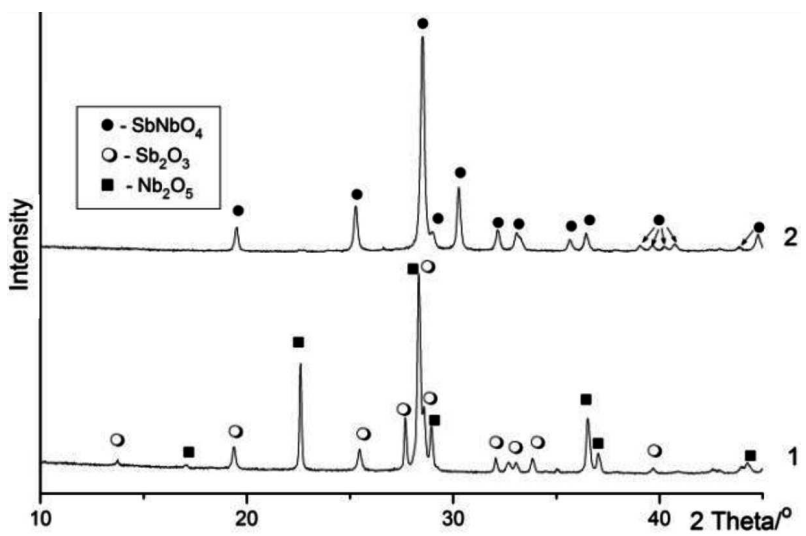

Fig. 2. Fragments of XRD diffractograms of (1) the equimolar mixture $\mathrm{Sb}_{2} \mathrm{O}_{3} / \mathrm{Nb}_{2} \mathrm{O}_{5}$ and (2) the compound $\mathrm{SbNbO}_{4}$ obtained from this mixture as a result of high-temperature synthesis.

Analysis of XRD diffractograms of the samples after the first $(1.5 \mathrm{~h})$ and second $(3 \mathrm{~h})$ stage of milling and after the first $\left(600^{\circ} \mathrm{C}-24 \mathrm{~h}\right)$ and second $\left(650^{\circ} \mathrm{C}-24 \mathrm{~h}\right)$ stage of heating permitted assigning their diffraction lines mainly to the set characterising the compounds $\mathrm{SbNbO}_{4}$ and $\mathrm{T}$ $\mathrm{Nb}_{2} \mathrm{O}_{5}$, with $\mathrm{SbNbO}_{4}$ the dominant phase. The samples should also contain the unreacted $\mathrm{Sb}_{2} \mathrm{O}_{3}$ which was not identified because of very low relative intensity of the XRD lines characterising this oxide in the diffractograms of the mixtures containing $\mathrm{SbNbO}_{4}$ and $\mathrm{T}_{-} \mathrm{Nb}_{2} \mathrm{O}_{5}$ (see Fig. 1).

The phase composition of all samples studied containing $\mathrm{SbNbO}_{4}$ proved that, irrespective of the method of synthesis, antimony(III) oxide reacts with niobium(V) oxide according to the equation 


$$
\mathrm{Sb}_{2} \mathrm{O}_{3(\mathrm{~s})}+\mathrm{Nb}_{2} \mathrm{O}_{5(\mathrm{~s})}=2 \mathrm{SbNbO}_{4(\mathrm{~s})} .
$$

In order to establish the thermal stability of $\mathrm{SbNbO}_{4}$, the monophase samples (HEM and HTS) were subjected to DTA-TG studies in argon and in air atmosphere.

The DTA curves of $\mathrm{SbNbO}_{4}$ obtained as a result of mechanochemical synthesis (Fig. 3) or a hightemperature reaction (Fig. 4) in argon atmosphere on heating up to $1300^{\circ} \mathrm{C}$ show one endothermic effect starting at $1125 \pm 10^{\circ} \mathrm{C}$.

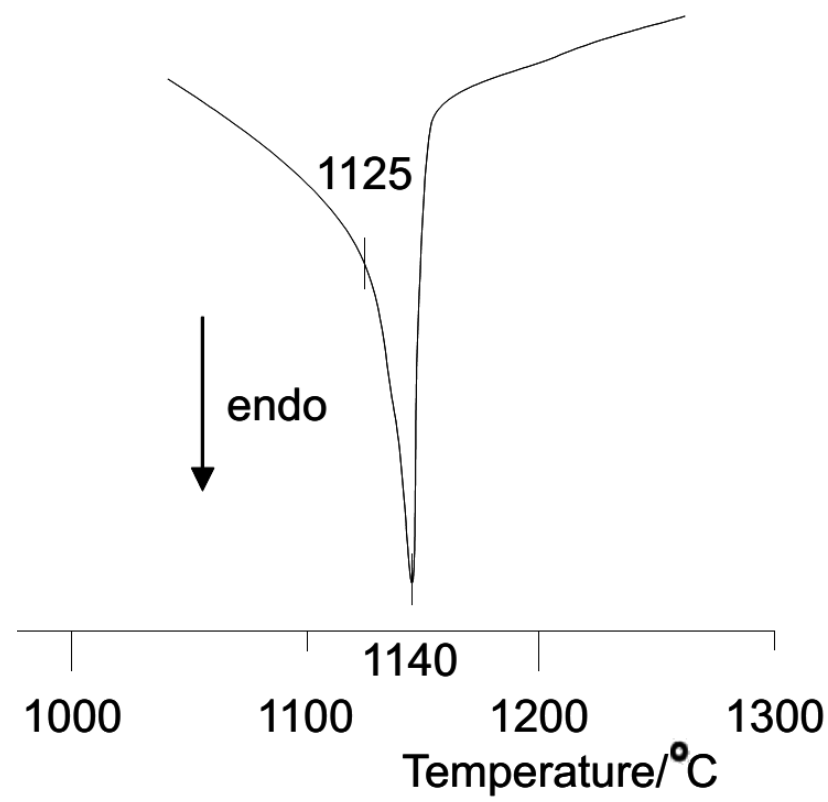

Fig. 3. The DTA curve of $\mathrm{SbNbO}_{4}$ in argon atmosphere (MChS).

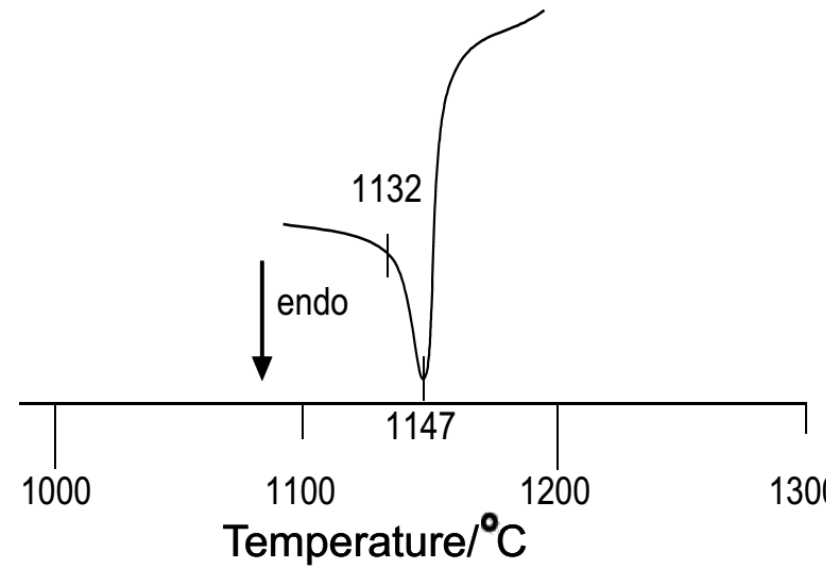

Fig. 4. The DTA curve of $\mathrm{SbNbO}_{4}$ in argon atmosphere (HTS).

On the basis of XRD results obtained for samples HEM and HTS, additionally heated at $1135^{\circ} \mathrm{C}$ for $2 \mathrm{~h}$ and then rapidly cooled to room temperature, the endothermic effect marked on DTA curves was attributed to incongruent melting of $\mathrm{SbNbO}_{4}$, according to the perytectic reaction
$\mathrm{SbNbO}_{4(\mathrm{~s})} \leftrightarrow \mathrm{H}-\mathrm{Nb}_{2} \mathrm{O}_{5(\mathrm{~s})}+$ liquid.

A solid product of $\mathrm{SbNbO}_{4}$ melting in anaerobic atmosphere is thus $\mathrm{H}-\mathrm{Nb}_{2} \mathrm{O}_{5}$.

The DTA curve recorded for $\mathrm{SbNbO}_{4}$ in air atmosphere, irrespective of the method of synthesis, revealed almost the same effects, see Fig. 5. The first broadened and poorly resolved exothermic effect starts at $\approx 780^{\circ} \mathrm{C}$, while the second endothermic one starting at 1040 has a clearly marked inflection point at $1060^{\circ} \mathrm{C}$.

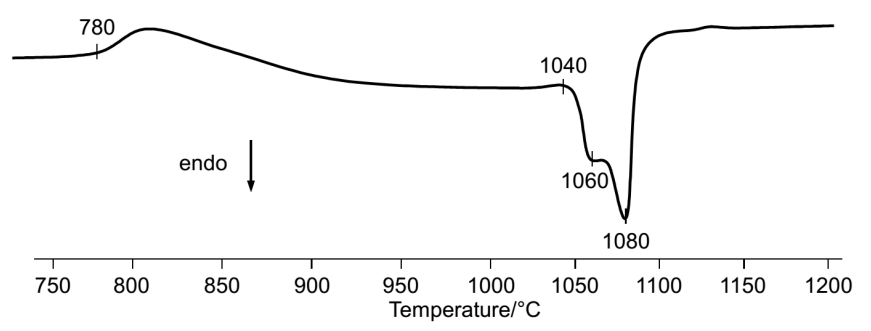

Fig. 5. The DTA curve of $\mathrm{SbNbO}_{4}$ in air atmosphere.

The XRD phase analysis of $\mathrm{SbNbO}_{4}$ heated in air at $800{ }^{\circ} \mathrm{C}$ for $2 \mathrm{~h}$ revealed the presence of $\alpha-\mathrm{Sb}_{2} \mathrm{O}_{4}$ and T$\mathrm{Nb}_{2} \mathrm{O}_{5}$. This result indicated that compound $\mathrm{SbNbO}_{4}$ is stable in air up to about $800^{\circ} \mathrm{C}$, then at higher temperatures it undergoes decomposition to the initial oxides, which is accompanied by oxidation of $\mathrm{Sb}_{2} \mathrm{O}_{3}$ to $\alpha-\mathrm{Sb}_{2} \mathrm{O}_{4}$. Additional heating of the products of $\mathrm{SbNbO}_{4}$ decomposition in air at $800^{\circ} \mathrm{C}$ for $48 \mathrm{~h}$ led to the formation of solid solutions $\mathrm{SbSb}_{1-x} \mathrm{Nb}_{x} \mathrm{O}_{4}$ and $\mathrm{Nb}_{2-x} \mathrm{Sb}_{x} \mathrm{O}_{5}$.

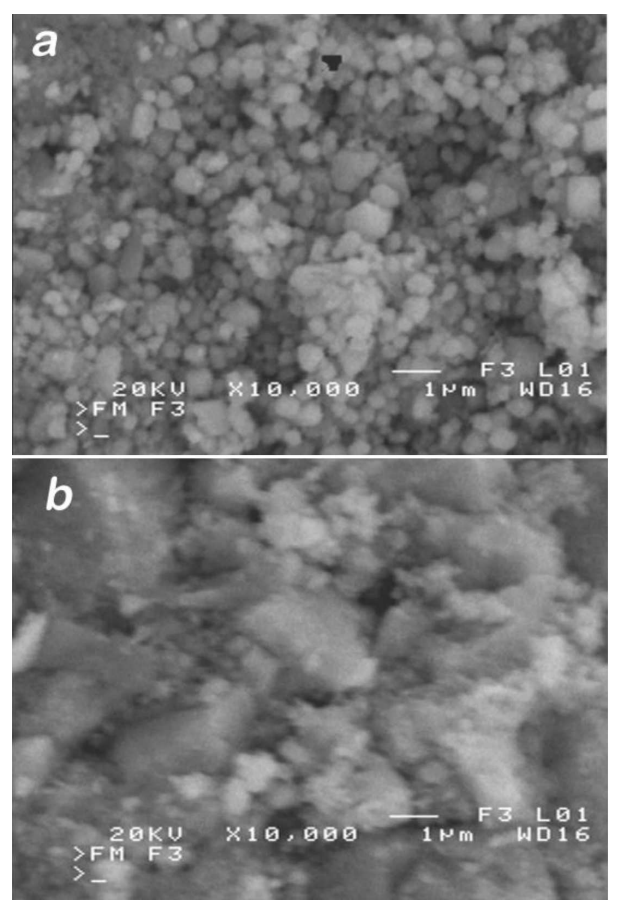

Fig. 6. SEM images of $\mathrm{SbNbO}_{4}$ synthesised by (a) high temperature and (b) mechanochemical method. 
At the next stage of the study, the compound $\mathrm{SbNbO}_{4}$ obtained by the two above-described methods was subjected to scanning electron microscopy (SEM). Figure 6a and $\mathrm{b}$ reveals differences in the morphology of $\mathrm{SbNbO}_{4}$ crystals obtained by the high-temperature reaction in solid phase (6a) and by mechanochemical synthesis $(6 \mathrm{~b})$. The compound $\mathrm{SbNbO}_{4}$ obtained by the mechanochemical synthesis has crystals of irregular shapes and inhomogeneous distribution of sizes. Unexpectedly, the largest crystals of $\mathrm{SbNbO}_{4}$ of poorly developed walls were those obtained by high-energy ball milling. Their size varied from $\approx 5 \mu \mathrm{m}$ to $0.1 \mu \mathrm{m}(100 \mathrm{~nm})$, while the size of crystals of this compound obtained by the high-temperature synthesis varied from 0.15 to $1 \mu \mathrm{m}$.

Taking into account the SEM images (Fig. 6b) and analysis of XRD line widths (Fig. $1-5 \mathrm{~h} \mathrm{MChS}$ ) obtained for $\mathrm{SbNbO}_{4}$ synthesised by mechanochemical method, it cannot be excluded that this product contains small amount of amorphous compound besides the crystal form of the compound.

It is worth noting that the resulting $\mathrm{SbNbO}_{4}$ by mechanochemical method had bright orange color when prepared by high temperature was white.

$\mathrm{SbNbO}_{4}$ synthesised by the two methods described above, samples HEM and HTS, have been subjected to IR study. The spectra of the two samples were almost identical. The only difference was that the absorption bands in the IR spectrum of the compound synthesised by the high-temperature treatment were slightly better developed (Fig. 7).

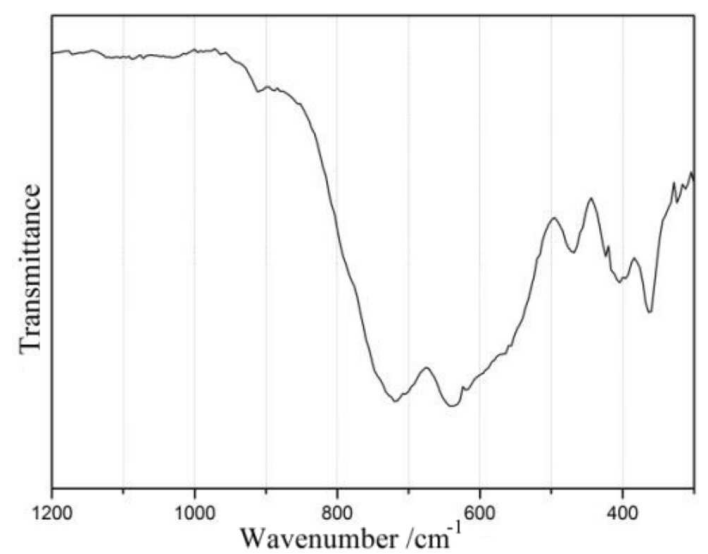

Fig. 7. IR spectrum of $\mathrm{SbNbO}_{4}$ obtained by hightemperature reaction.

The IR spectrum of $\mathrm{SbNbO}_{4}$ shows the absorption bands of the maxima at $720,636,616,468,424,404$ and $364 \mathrm{~cm}^{-1}$. On the basis of literature, the bands with the maxima at $720,636,616$ and $468 \mathrm{~cm}^{-1}$, can be with a high probability assigned to the stretching vibrations $(\nu)$ of $\mathrm{M}-\mathrm{O}$ bonds in the $\mathrm{NbO}_{6}$ octahedrons and in strongly deformed $\mathrm{SbO}_{6}$ octahedrons [19-23]. The bands peaking at 720 and $468 \mathrm{~cm}^{-1}$ are assigned to the stretching vibrations of $\mathrm{Nb}-\mathrm{O}$ bond with the oxygen atom joining two $\mathrm{NbO}_{6}$ octahedrons via a shared vortex. The bands peaking at 324 and $310 \mathrm{~cm}^{-1}$ correspond to the deformation vibrations $(\delta) \mathrm{O}-\mathrm{M}-\mathrm{O}$ in $\mathrm{SbO}_{6}$ and $\mathrm{NbO}_{6}$ polyhedrons sharing edges and vortices [21-23]. This quantitative analysis of the IR spectrum of $\mathrm{SbNbO}_{4}$ is in good agreement with literature data [7-9] implying that the structure of this compound contains joined $\mathrm{NbO}_{6}$ octahedrons and strongly deformed $\mathrm{SbO}_{6}$ octahedrons.

\section{Conclusions}

1. The compound $\mathrm{SbNbO}_{4}$ can be obtained from equimolar mixture of $\mathrm{Sb}_{2} \mathrm{O}_{3} / \mathrm{Nb}_{2} \mathrm{O}_{5}$ as a result of solid state reaction in argon atmosphere not only by the high-temperature treatment but also by a much shorter and easier process of high-energy ball milling.

2. Unexpectedly, the mean size of $\mathrm{SbNbO}_{4}$ crystals obtained by the mechanochemical method is much greater than that of the crystals obtained by hightemperature treatment.

3. Irrespective of the method of synthesis, $\mathrm{SbNbO}_{4}$ is stable in argon atmosphere up to $\approx 1125^{\circ} \mathrm{C}$, above which it undergoes incongruent melting with development of solid state $\mathrm{H}-\mathrm{Nb}_{2} \mathrm{O}_{5}$, while in air atmosphere at $\approx 800{ }^{\circ} \mathrm{C}$ it undergoes decomposition to $\mathrm{Sb}_{2} \mathrm{O}_{3}$ and $\mathrm{Nb}_{2} \mathrm{O}_{5}$ accompanied by oxidation of $\mathrm{Sb}_{2} \mathrm{O}_{3}$ to $\alpha-\mathrm{Sb}_{2} \mathrm{O}_{4}$.

4. IR spectra confirmed that the compound obtained by the two methods is built of $\mathrm{NbO}_{6}$ octahedrons and strongly deformed $\mathrm{SbO}_{6}$ octahedrons.

\section{Acknowledgments}

This study was supported by the projects DEC$2012 / 05 / \mathrm{N} / \mathrm{ST} 8 / 03764$ (National Science Centre Poland) and DS/C-1/KWC/2014 ZUT/BMN 517-10020-3604/17 (Polish Ministry of Science and Higher Education).

\section{References}

[1] C. Keller, Z. Anorg. Allg. Chem. 318, 89 (1962) (in German).

[2] R.S. Roth, J.L Waring, Am. Mineral. 48, 1348 (1963).

[3] V.I. Popolitov, Inorg. Mater. 32, 228 (1996) (in Russian).

[4] V.I. Popolitov, A.N. Lobachev, V.F. Peskin, L.N. Sirkin, N.N. Feoktistova, Kristallographiya 19, 573 (1974) (in Russian).

[5] V.I. Popolitov, L.A. Ivanova, S.Yu. Stephanovitch, V.V. Chetchkin, A.N. Lobachev, Yu.N. Venevtsev, Ferroelectrics 8, 519 (1974).

[6] A.M. Sych, V.I. Popolitov, L.A. Eremenko, Zh. Neorg. Khimii 19, 2397 (1974) (in Russian). 
[7] V.I. Ponomarev, O.S. Filipenko, L.O. Atovmyan, N.V. Rannev, S.A. Ivanov, Yu.N. Venevtsev, Kristallographiya 26, 341 (1981) (in Russian).

[8] A.C. Skapski, D. Rogers, J. Chem. Soc. Chem. Commun. 23, 611 (1965).

[9] S.H. Kim, S. Park, Ch.W. Lee, B.S. Han, S.W. Seo, J.S. Kim, I.S. Cho, K.S. Hong, Int. J. Hydrog. En. 37, 16895 (2012)

[10] T.N. Blanton, C.L. Barnes, D.J. Eichorst, Powder Diffr. 8, 188 (1993).

[11] D. Zhou, H. Wang, H. Zhou, X. Xie, X. Yao, Y. Cheng, J. Mater. Sci. 42, 8387 (2007)

[12] A.C. Skapski, Acta Chem. Scand. 20, 580 (1966).

[13] K.M. Ok, N.S.P. Bhuvanesh, Shiv P. Halasyamani, J. Solid State Chem. 161, 57 (2001).

[14] P. Baláž, M. Achimovičová , M. Baláž, P. Billik, Z. Cherkezova-Zheleva, J. Manuel Criado, F. Delogu, E. Dutková , E. Gaffet, F.J. Gotor, R. Kumar, I. Mitov, T. Rojac, M. Senna, A. Streletskii, K. WieczorekCiurowa, Chem. Soc. Rev. 42, 7571 (2013).
[15] E. Filipek, G. Dąbrowska, J. Alloys Comp. 523, 102 (2012).

[16] E. Filipek, G. Dąbrowska, M. Piz, J. Alloys Comp. 490, 93 (2010).

[17] P. Dulian, W. Bąk, K. Wieczorek-Ciurowa, Cz. Kajtoch, Mater. Sci.-Poland 31, 462 (2013).

[18] J. Rakoczy, J. Nizioł, K. Wieczorek-Ciurowa, P. Dulian, React. Kinet. Mech. Catal. 108, 81 (2013).

[19] S. Bahfenne, R.L. Frost, Appl. Spectrosc. Rev. 45, $101(2010)$.

[20] S.J. Gilliam, J.O. Jensen, A. Banerjee, D. Zeroka, S.J. Kirkby, C.N. Merrow, Spectrochim. Acta A 60, 425 (2004)

[21] M. Ziolek, I. Nowak, Catal. Today 78, 543 (2003).

[22] N. Ballarini, F. Cavani, C. Giunchi, S. Masetti, F. Trifiro, D. Ghisletti, U. Cornaro, R. Catani, Top. Catal. 15, 111 (2001).

[23] E. Filipek, M. Kurzawa, G. Dąbrowska, J. Therm. Anal. Calorim. 60, 167 (2000). 